\title{
Towards a contextual approach to the place-homeless survival nexus: An exploratory case study of Los Angeles County
}

\author{
Matthew D. Marr*, Geoff DeVerteuil, David Snow \\ Florida International University, Department of Global and Sociocultural Studies, Asian Studies DM 312, University Park Campus, Miami, FL 33199, United States
}

\section{A R T I C L E I N F O}

\section{Article history:}

Received 8 May 2009

Received in revised form 28 July 2009

Accepted 29 July 2009

Available online $\mathrm{xxxx}$

\section{Keywords:}

Homelessness

Survival

Adaptation

Subsistence

Space

Place

\begin{abstract}
A B S T R A C T
The characteristics of the immediate locale greatly affect the ability of homeless people to adapt to life on the street and in shelters, with different types of places nurturing different circumstances for survival. Current conceptualizations of the place-survival nexus are too narrow, relying on small-scale, intensive studies of particular places that are known to sustain homeless survival while ignoring more suburban and exurban locales, as well as failing to set these places of survival within the larger socio-economic spaces of the metropolitan area. Further, the literature is heavily qualitative, lacking any kind of "big picture" quantitative assessment of the nexus. In response, we contribute to the place-survival nexus literature by developing a typology of space for homeless survival and then use interview data to examine the variation in survival strategies across three types of urban space in Los Angeles County. Our results speak to how our innovative and exploratory approach enabled a broader, more extensive and variegated understanding of place-survival among homeless people than previous studies.
\end{abstract}

(c) 2009 Elsevier Ltd. All rights reserved.

\section{Introduction}

Survival among people experiencing homelessness is understood to be far more precarious than for the housed population (Wolch and Dear, 1993). Recently, and spurred by worries about their image, public safety and livability, local governments and businesses have systematically implemented anti-homeless ordinances to outlaw certain behaviors and survival techniques in public spaces, including panhandling, camping, sleeping, sitting, loitering, urinating and, in some cases, even providing free meals to the hungry (Mitchell, 1997; Merrifield, 2000; National Coalition for the Homeless, 2007). Residential communities have also resisted development of shelters and other housing programs, causing them to be concentrated in some neighborhoods and excluded from others (Takahashi, 1999). While we should not overestimate the impacts of these trends upon a group that is often very resilient (DeVerteuil, 2006), they nonetheless have presented additional challenges to persons living in public space and shelters.

This context makes understanding the nexus between place and homeless survival all the more important. Since homeless people are resource-poor by definition, the characteristics of the immediate locale greatly affect their ability to adapt to life on the street and in shelters (Wolch and Dear, 1993). Moreover, different types of places nurture different circumstances for survival. But we also contend that current conceptualizations of the place-survival

\footnotetext{
* Corresponding author. Tel.: +1 305348 4004; fax: +1 3053483605 .

E-mail address: mmarr@fiu.edu (M.D. Marr).
}

nexus are too narrow, relying heavily on small-scale, intensive studies of particular places that are known to sustain homeless survival. The current literature also does not set these places of survival within the larger socio-economic spaces of the metropolitan area. Last, the literature is heavily qualitative, lacking any kind of "big picture" quantitative assessment of the nexus.

In this paper, we contribute to the place-survival nexus literature by addressing these gaps through an innovative approach that develops a typology of space for homeless survival and then uses interview data $(n=25)$ to examine the variation in survival strategies among our respondents across three types of urban space in Los Angeles County. Our exploratory research focuses on whether our innovative approach enables a broader, more extensive and variegated understanding of place-survival among homeless people than previous studies. To this end, we first outline the homeless survival literature, emphasizing that not all places ensure survival equally. We then re-conceptualize the place-survival nexus by proposing a broader, more mixed-methods approach. As a backdrop to our study, we sketch the larger context of homelessness within Los Angeles County. Next, we outline our research procedures and analytic techniques, specifically (1) the development of a cluster analysis that categorizes Los Angeles County into prime, transitional, and marginal spaces, and (2) the survival patterns within the three spaces derived from our in-depth interviews of twenty-five homeless informants. We then present and elaborate the results of the cluster analysis and its interplay with relevant interview materials, focusing on the multifaceted survival patterns of homeless people within the three cluster spaces. Finally, we 
discuss the utility of our innovative approach in terms of expanding our understanding the place-survival nexus.

\section{The place-homeless survival nexus}

There is an extensive literature on how homeless people materially survive and adapt to their circumstances (Baldwin, 1998; Cohen and Sokolovsky, 1989; Dordick, 1997; Duneier, 1999; Gounis, 1992; Hopper, 2003; Hopper et al., 1985; Koegel et al., 1999; Passaro, 1996; Rollinson, 1990; Rowe and Wolch, 1990; Ruddick, 1996; Snow and Anderson, 1993; Wolch and Dear, 1993; Wright, 1997). We wish to highlight two points that connect homeless survival with the crucial role of place. First, place matters for material survival, in profound and direct ways. Wolch and Dear (1993, p. 246) argue that "coping on the outside...[is] inextricably linked to the qualities of the local context." Not all places ensure survival equally; only a few work especially well, those that Duneier (1999) deems

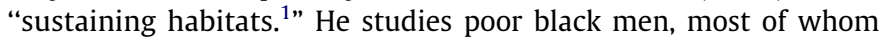
were living in public spaces in and around Sixth Avenue in New York City's Greenwich Village, and how this area became such a wellworking place-survival nexus. Among the questions Duneier seeks to answer is why these men congregate around this area of Sixth Avenue after their eviction from Penn Station. His answer is that this area fits the personal preferences and resource availability of the men, that it is a resource-rich and accepting place that constitutes a sustaining environment for homeless people. The latter includes a number of elements, none of which is necessary, but are sustaining because of their complementarity: heavy pedestrian traffic for panhandling; cheap or free food; a generally sympathetic community willing to make donations; safe and open public spaces in which to sleep; opportunities to scavenge; nearby services (shelters, food pantries, etc.) for homeless people; and hiding places ("niches") that can be used for privacy (Duneier, 1999, pp. 144-153). Although we cannot generalize his concept to other places, we can use it as an example of where the place-survival nexus works particularly well to meet immediate needs amid homelessness. Sustaining environments may not necessarily facilitate an exit from homelessness, as this depends more on housing and employment opportunities (Marr, 2007). Going further, Dordick (1997) argues that homeless places are not merely "stations" but constitute life-worlds unto themselves, powerfully structuring subsistence patterns and strategies. For instance, using a private shelter implied more consistent survival patterns, especially regarding food and shelter, but also greater constraints on personal freedom, while more informal settings, such as encampments, enabled the development of intensive personal relationships while also constraining the ability to secure basic subsistence. One analytic implication from Duneier (1999) and Dordick (1997) is that the distribution of homeless people and their adaptive behaviors are place-contingent, with places within a larger space being differentially supportive or nutrient of homeless subsistence.

Second, homeless people have a role to play in the creation and persistence of favorable place-survival nexuses, suggesting some agency. While all human agency is constrained, homeless agency is especially constrained. Although various structural constraints may impede survival patterns, homeless individuals may also exercise considerable discretion. As Snow and Anderson (1993, p. 21) observe, "Repertoires of survival strategies [for homeless people] do not emerge willy-nilly. They are the product of the interplay between the resourcefulness and ingenuity of homeless people and local organizational, political, and ecological constraints." Hopper (2003) uses extensive fieldwork in 1970s and 1980s New York City

\footnotetext{
${ }^{1}$ In the remainder of the paper when we refer to Duneier's concept, we use "environments" rather than "habitats," given the danger of the latter to imply more primitive, animal-like survival strategies among persons experiencing homelessness compared to those who are more stably housed.
}

to show that many individuals would logically forgo staying in large public shelters due to widespread violence, illness, and demoralizing treatment by staff in favor of the dignity and autonomy of the streets and particular niches such as a municipal airport. Further, Duneier (1999) shows how broad political contexts, like legal efforts to support the right to sell written material on city sidewalks based originally on First Amendment rights, can enable and constrain certain survival strategies often in unintended ways, in this case promoting the practice of selling recycled books and magazines among homeless people. The concept of "constrained agency" balances the notion of homeless people as "active, rational and competent actors engaged in negotiating their social world" (Molina, 1998, p. ix) with fundamental structural constraints (e.g. extreme poverty, excessive unemployment, lack of affordable housing, regulation of public spaces) that set boundaries to all behavioral choices.

Despite the richness of the literature on the place-survival nexus, there remain three key and inter-related gaps. First, current conceptualizations of the place-survival nexus are too narrow, focusing only on small-scale, intensive studies of known sustaining environments. We know relatively little about how homeless people go about surviving in less resource-rich neighborhoods that may include suburban and even exurban/rural (Cloke et al., 2002), ethnic, transitional or even exclusive areas. Second, the current literature does not set these places of survival within the larger socio-economic spaces of the metropolitan area, preferring instead micro-studies of particular neighborhoods. The importance of embedding places of survival within broader socio-economic spaces of the extended city lies in simultaneously understanding micro-level and macro-level processes. Third, the current literature is heavily qualitative and intensive, lacking any kind of "big picture" quantitative assessment of the nexus. This means that current research is not easily replicable, nor is it amenable to linking the places of survival with the broader socio-economic spaces of the city. There remains a need, in sociology and urban studies, to combine the strengths of both quantitative and qualitative approaches to clearly demonstrate the interaction between macro-level social relations reflected in urban spaces and micro-level lived experiences of places.

\section{Reconceptualizing the nexus}

We begin addressing these gaps through an innovative approach to understanding the broader context of the place-homeless survival nexus. This approach combines (1) a typology of urban space that moves well beyond the typically resource-rich neighborhood study that currently characterizes the literature; (2) the application of a quantitative technique to map such a typology over a much larger geographic space, thus analyzing macro-social spatial relations; and (3) analysis of qualitative life-history interviews to demonstrate the linkages between macro and micro level social processes. Ultimately, we are interested in whether our innovative approach actually enables a potentially broader understanding of the place-survival nexus. By this we mean a more extensive and more variegated understanding than in the existing literature. We explore the following questions: How do different spaces theoretically allow for different survival strategies/sustaining environments? How does homeless survival proceed in less than promising locales, given that most of our current knowledge only examines locales that intuitively support survival?

First, and building on the earlier work of Duncan (1983), Snow and Anderson (1993) and Logan and Molotch (1987), we employ Snow and Mulcahy's (2001) categorization of urban space into prime, marginal, and transitional. Prime space refers to mainstream spaces used by the socio-economically well-off population, entrepreneurs and politicians for everyday, commercial and 
symbolic purposes. Conversely, marginal space has little value to these groups, but can be readily transformed into prime space, as often occurs with redevelopment and gentrification. Transitional space $^{2}$ represents a middle ground by functioning to combine both prime and marginal uses and/or to act as a buffer between the two. For homeless people, marginal space is essential, as it contains much of their sustaining resources, including spaces to camp or sleep rough with relatively low probability of police interference, shelters, cheap hotels, services and affordable, albeit unattractive housing. The distribution and availability of marginal space is thus critical in shaping the how and where of homeless survival patterns. However, the proximity of prime space is also important, as it provides opportunities for scavenging, recycling and especially panhandling that may not exist in marginal spaces themselves. These opportunities are usually connected to thriving commercial districts. Crucially then, each of these spaces has varied characteristics for sustaining homeless individuals and their survival practices. These expectations on the relationship between the resource availability in marginal, transitional and prime spaces and individual agency and survival techniques play in to each other, with neither necessarily determining the other. In other words, homeless people may select specific spaces to survive in, but that those spaces offer certain constraints.

Second, we employ a $k$-means cluster analysis to categorize urban space according to Snow and Mulcahy's (2001) tripartite division. This statistical procedure is commonly used in geo-demographics as a data reduction technique to identify relatively homogeneous groups of observations based on selected variables. As a non-hierarchical and unsupervised technique, $k$-means cluster analysis requires an a priori specification of the number of clusters (Rogerson, 2001); in our case it will be the three pre-designated spaces (marginal, transitional and prime). The use of a $k$-means cluster analysis maximizes intra-group cohesion and inter-group variability, allows for replication, and serves as an efficient tool to categorize and reduce the massive amount of socio-economic data associated with complex and multifaceted global city-regions. We combine the tripartite categorization of space, using the $k$ means cluster analysis, to a far more extensive geographical area than previously studied in the literature. This is innovative because almost all previous studies are narrowly micro-level in nature. We apply this alternative approach to the place-survival nexus within the Los Angeles County metropolitan area at the census tract level, using 2000 Census data.

Third, we merge the results of the cluster analysis with qualitative life histories, so as to examine some of the interplay between the lived experiences of the place-survival nexus and the broader socio-economic spaces of the city, thereby constituting a crucial component of our innovative approach to the place-homeless survival nexus. Given that only 25 homeless individuals were interviewed, we cannot claim strong relationships between marginal, transitional and prime spaces and typical survival behavior therein. Rather, we seek to identify the key features of each space in terms of the place-survival nexus, including which clusters provided more structured and stable material survival than others. Before the analysis, however, we need to provide some background on the context of homelessness in Los Angeles County.

\section{The context of homelessness in los angeles county}

Our goal here is to briefly provide the context of homelessness in our case study - Los Angeles County - and explore some of the associations with the three kinds of spaces. Los Angeles County is the most populous in the United States, with an estimated 9.8 mil-

\footnotetext{
2 This transitional space is dissimilar to the Chicago School's "zone in transition," in that the former represents an in-between space - neither marginal nor prime (Park and Burgess, 1925)
}

lion inhabitants in July 2007 (US Census Bureau, 2008) and 88 municipalities and numerous unincorporated areas. The point-intime homeless population is also seen to be the largest in absolute numbers in the nation, including at least 88,000 people in 2005 , as well as being high in per-capita terms (LAHSA, 2006).

Across such a complex environment, homeless people have adapted to a wide variety of places, some more favorable to material survival than others. These range from the city's dingy and crowded Downtown Skid Row to upscale beach communities, down-at-the-heels inner suburbs, and distant defense-dependent exurbs on the region's fringe. Across these sharply differentiated settings, homeless people encounter vastly different resources and constraints. Some places are heavily institutionalized, characterized by large-scale shelters and other social services; other places are virtually devoid of formal services, but offer other, less formalized places and resources that can facilitate the survival of some homeless individuals. Such wide-ranging environmental differences in place intersect with individual-level differences in human and social capital and demographic and biographic characteristics and vulnerabilities to shape adaptation patterns to living on the streets or in shelters.

The largest concentrations of homeless individuals are found in older, denser and heterogeneous inner-city neighborhoods, where homeless services tend to cluster in "service hubs" (Dear et al., 1994; DeVerteuil, 2006). Of these, the largest is Skid Row in Downtown Los Angeles, where a disproportionate array of shelters, Single-Room Occupancy (SRO) hotels, drop-in centers and substance abuse treatment facilities are concentrated. In 2000, this 50-square block area held $25 \%$ of the County's over 13,000 shelter beds (CCA, 2002; DeVerteuil, 2006).

The ecological constraints and conditions that affect the character, concentration, and distribution of the place-survival nexus must necessarily be framed within a larger political-economic context. Increasing numbers of precariously-housed individuals in Los Angeles County became homeless in the 1980s as a result of the intersection of global, national, and local forces and conditions (Davis, 1992; Wolch and Dear, 1993; Wolch and DeVerteuil, 2001). This growth generated various responses at the local level, ranging from highly supportive to overtly punitive. A 1991 Los Angeles County survey of 83 cities identified three specific types of responses: homelessness as a problem of social control (i.e. homeless people are disorderly and must be contained, controlled, etc.), homelessness as a social welfare crisis (i.e. local governments ought to provide services to needy residents who "become homeless for more structural reasons"), and homelessness as a problem of zoning and land-use planning (i.e. homelessness is primarily a technical and locational issue of balancing the needs of clients with other land users) (Law, 2001). Since 1991, however, the number and visibility of homeless people in Los Angeles have clashed with redevelopment visions and engendered a series of institutional backlashes (Wolch and DeVerteuil, 2001). While prime spaces in the County have always been hostile to homeless people, services for them and poor people more generally, it was not until the early 2000s that a similar intransigence emerged within marginal and transitional spaces. Since the late 1990s, several marginal and transitional spaces - such as Hollywood, the historic core of Downtown, and Downtown Long Beach - have been revitalizing, hand in hand with growing anti-homeless activity (Wolch, 2008). As a result, homeless people are at greater risk of being evicted from public space. Still, we should be careful not to overstate the extent to which these pressures have actually translated into permanent displacement of homeless people, given their tenacity and ingenuity. Our interviews occurred in 2003, just when this added pressure was becoming apparent at street level. It is within and in response to this context, and particularly the ongoing scramble for shelter of some kind, that the survival strategies of homeless people emerge. 


\section{Data and procedures}

\section{Cluster analysis}

We used a non-hierarchical $k$-means cluster algorithm to identify Snow and Mulcahy's (2001) prime, marginal, and transitional spaces in Los Angeles County, based on socio-economic variables from the 2000 Census at the census tract level. Ten variables from the 2000 Census were chosen for their ability to distinguish prime spaces occupied by largely white, high-income, well-educated and native-born inhabitants, and marginal spaces occupied by largely non-white, high-immigrant, low-education and low-income inhabitants, the key divisions said to characterize polarized global city-regions such as Los Angeles (Sassen, 2001; Scott, 2001). Once identified, we profiled these spaces according to their ability to sustain homeless survival, focusing on the location of emergency shelters using an extensive database maintained by a local nonprofit organization (Shelter Partnership, 2000). Although not all homeless people rely on shelters, they do constitute a critical node for survival for many (Burt et al., 2001; Hopper et al., 1985).

We sought census variables that would cover race, poverty, citizenship and language, and housing status, all elements of the global city-region polarization thesis that posits large gaps between welleducated elites and recent immigrant, low-wage populations. The specific variables were (see also Rogerson, 2001; DeVerteuil, 2005 for the use of the following variables): (1) Race - percentage White non-Hispanic (one race response); (2) Income $e^{3}$ - percentage of households on public assistance (general assistance, or General Relief as it is called in Los Angeles, and Temporary Aid to Needy Families, but not inkind assistance or Supplemental Security Income) and percentage of population under the poverty line; (3) Citizenship/language - percentage of households who are linguistically isolated (i.e. a household in which all members 14 years or older speak a non-English language and also speak English less than "very well"), percentage of total population who are recent immigrants, (i.e. year of entry between 1990 and March 2000), and percentage of total population who are American citizens; (4) Housing - percentage of occupied units that are owned, percentage of occupied units with 2 or more occupants per room (to measure overcrowding), and percentage of occupied units that are single, detached units; and (5) Education - percentage of population over 25 with a university degree. These clusters capture not only difference in income level but also difference in access to political resources (affected by race, education, citizenship, English ability, etc.) necessary to shape responses to homelessness within local spaces, importantly the ability to engage in NIMBY ("not in my back yard") resistance to services for the homeless.

Each of the percentage variables was standardized into $Z$-scores (Rogerson, 2001). The resulting cluster analysis was validated for goodness-of-fit through an ANOVA F-statistic, particularly how well-separated the clusters were from each other and how well each variable is contributing to the success of the clustering (Levia and Page, 2000; Rogerson, 2001). After the results of the cluster analysis were mapped onto the 2054 census tracts of Los Angeles County, the location of a key homeless service - emergency shelter beds - was mapped onto the three clusters using a GIS geocoding technique.

\section{Life-history interviews}

While the cluster analysis provides a County-wide portrait or map of different spaces for homeless people, it does not help us understand the interplay between these broad spaces and the ac-

\footnotetext{
${ }^{3}$ Household income was not used because we are focused more on evidence of poverty, which is already measured by public assistance and poverty rates. Moreover, household income on its own does not take into account the expense of basic goods, which the poverty rate does.
}

tual place of homeless survival, and between the constraints of the cluster spaces and the individual's ability to select the appropriate space for survival. To this end, we draw on 25 in-depth, life-history interviews with homeless informants across these spaces in Los Angeles County. These interviews were part of a larger project focusing on the causes, demographics, survival strategies, and politics of homelessness in four global cities - Los Angeles, Paris, Sao Paulo, and Tokyo. For this paper, we analyze only the interviews from Los Angeles in order to develop our innovative approach to the place-homeless survival nexus. The interviews sought to elicit elaborated biographic commentary from the homeless informants in response to a host of open-ended questions regarding their (a) current living situation, (b) causes/accounts of homelessness, (c) family background and childhood, (d) material subsistence, (e) daily routines, (f) efforts to get into stable housing; and (h) demographic characteristics. The interviews ranged in time from around an hour to over three hours, but averaged approximately 90 minutes. All respondents received $\$ 20$ for their time.

Our sampling strategy was purposive rather than random or probability-based. Purposive sampling is most appropriate when population parameters are unknown or difficult to discern, as with the homeless population in any given city, and/or when there is interest in learning about select cases or variation across a set of cases or category of individuals. Since our interest was to learn, among other things, about the variability among homeless people in their survival strategies and adaptive behaviors across different spaces, we employed a purposive field sampling strategy called maximum variation sampling (Lofland et al., 2006, pp. 91-93). It is a sampling strategy that identifies the diversity or range of the phenomena of interest so as not to miss various forms or types of adaptation. The implication for studying people who are homeless is to identify the various niches or contexts in which they might be found and then try to include individuals associated with those niches in the field sample. By broadening the sampling net in this fashion, even if a few niches are missed, we increase understanding of the range and variation of the phenomenon of interest.

In our application of purposive sampling, conducted before the mapping of spatial types on the County, we recruited individuals across Los Angeles' vast landscape and in areas known for varying densities of homeless services and homeless sub-populations (using databases from Shelter Partnership, 2000; LAHSA, 2006). Also, we ensured that we interviewed a number of persons in all eight of Los Angeles' Service Planning Areas, divisions of the County used for health care and other social service planning. Thus, we sought out interview respondents across obvious "service hubs" (see Fig. 2) such as Skid Row and Santa Monica, in suburban areas with moderate amounts of services such as Downtown Long Beach and the San Fernando Valley, in inner-city areas with high need but relatively low levels of services such as South-Central Los Angeles, and in areas with few to almost no services like the Beach Cities. In the vast majority of cases (22 of 25 ), we contacted interviewees through service providers such as shelters, transitional housing programs, drop-in centers, and street outreach teams. In an attempt to incorporate the small proportion of persons with no use of homeless services (Burt et al., 2001), we contacted three interview informants directly in parks and other public spaces.

Through the interview materials and subsequent analysis we were able to identify for each individual the location of their primary sustaining environment. Although a few informants described extensive mobility across census tracts, the vast majority was limited in their mobility and, given the tendency of adjacent tracts to fall in similar spatial types, conducted most of their daily activities within a particular spatial type. After we had mapped the three clusters onto the spaces of Los Angeles County, we grouped 
our informants according to which spatial type they resided in (where they slept) at the time of the interview. To render the interview material meaningful, we coded data according to an individual's demographic profile, vulnerabilities, and their strategies in meeting material challenges. After the data were coded, we searched for patterns and variations in survival strategies within each of the clusters.

\section{Results}

\section{Cluster analysis}

Table 1 outlines the three general spatial categories in Los Angeles County, clustered in terms of selected socio-demographic and

Table 1

Characteristics of spatial clusters (in percent). Source: 2000 Census Data.

\begin{tabular}{lllc}
\hline $\begin{array}{l}\text { Selected socio-demographic and } \\
\text { economic characteristics }\end{array}$ & $\begin{array}{l}\text { Cluster 1 } \\
\text { marginal }\end{array}$ & $\begin{array}{l}\text { Cluster 2 } \\
\text { transitional }\end{array}$ & $\begin{array}{l}\text { Cluster 3 } \\
\text { prime }\end{array}$ \\
\hline White non-Hispanic & 7.4 & 20.3 & 60.7 \\
Households on public assistance & 13.8 & 7.2 & 2.2 \\
Residents in poverty & 33.7 & 18 & 6.6 \\
Residents linguistically isolated & 34.5 & 15 & 5.6 \\
Recent immigrants & 22.2 & 11.9 & 5.8 \\
American citizens & 60.4 & 76.4 & 90 \\
Owner-occupied housing & 21 & 45.1 & 67.2 \\
Two or more persons per room & 21.5 & 8.1 & 1 \\
Single detached housing & 31 & 56 & 72.6 \\
University degree & 11.1 & 22.8 & 47.6 \\
\hline
\end{tabular}

economic characteristics. We found that all of the variables had high and significant F-values (between 444 and 2198), roughly indicating the success of the technique in differentiating the three clusters, as well as the success of each variable in contributing to the overall differentiation. The cluster spaces can be understood as a rough socio-economic gradient, moving from largely nonwhite, poor, heavily immigrant, overcrowded, renter and undereducated areas (Cluster 1) to largely white, middle/upper class, American-born, owner and well-educated areas (Cluster 3), reflecting the broad outlines of the global city-region polarization thesis (Sassen, 2001; Scott, 2001). Cluster 2 most approaches County median values.

Table 1 further confirms the deep socio-economic polarization within Los Angeles County, the spatial distribution of which becomes more obvious when the clusters are mapped by census tract (Fig. 1).

The data shown in Table 1 and Fig. 1 provide an overall profile of each cluster. Beginning roughly at the center of the County, Cluster 1 represents marginal spaces. This cluster included the largely immigrant, impoverished and contiguous core of Los Angeles County. Cluster 2 (transitional spaces) is largely contiguous to Cluster 1 areas but generally inner-suburban areas with mixed-income and less heavily immigrant populations. These areas are lower in density, ethnically mixed, and at risk of upward or downward filtering. Finally, Cluster 3 occupies the outer ring (prime spaces) including foothill and beach communities, as well as certain inner areas that have maintained their socio-economic integrity.

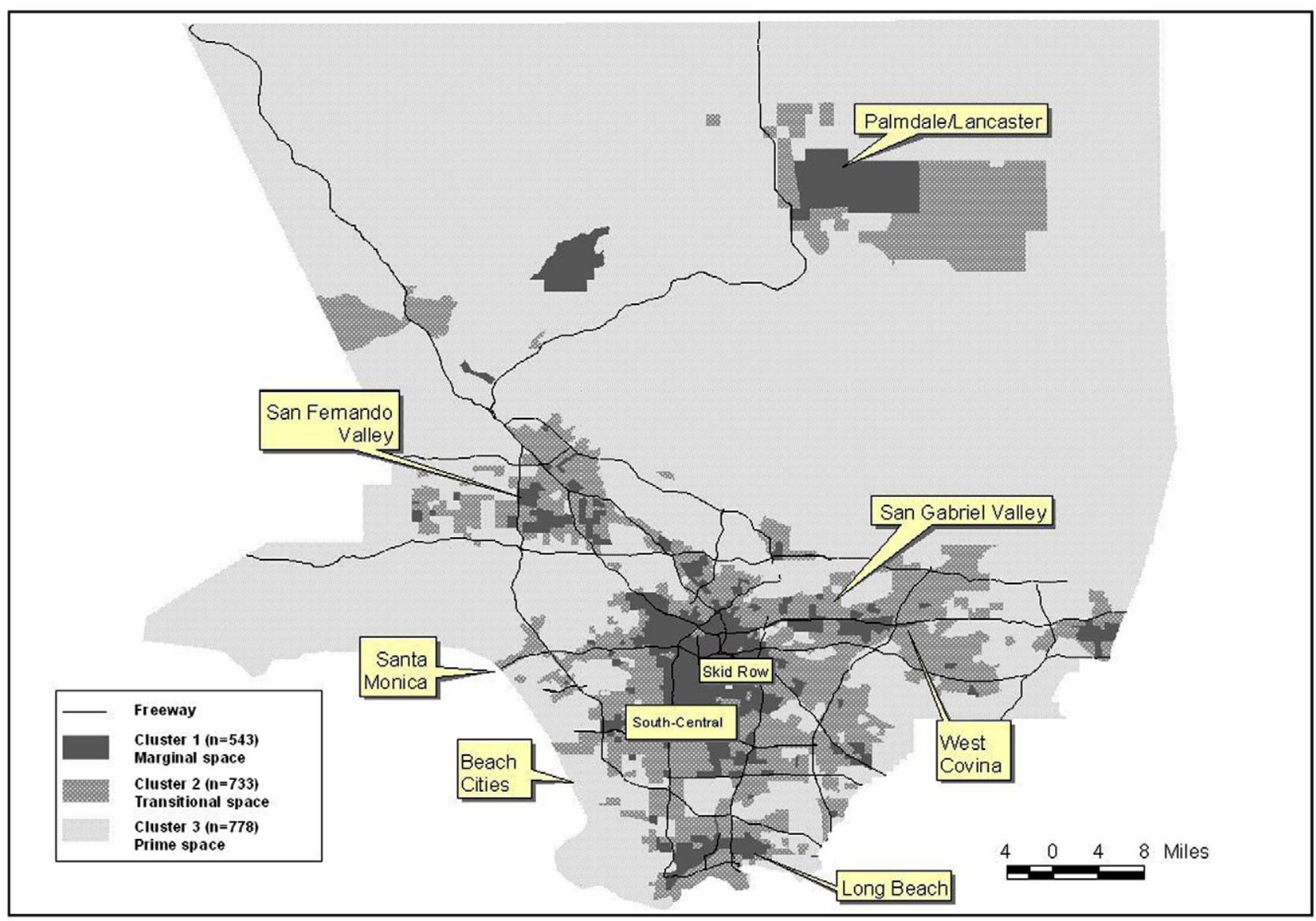

Source: US Census 2000

Fig. 1. Prime, transitional and marginal spaces in Los Angeles County by census tract. 
Table 2

Share of total county shelter beds by cluster. Source: Shelter Partnership (2000) and US Census 2000.

\begin{tabular}{lcll}
\hline & $\begin{array}{l}\text { Total } \\
\text { number } \\
\text { of beds }\end{array}$ & $\begin{array}{l}\text { Percentage of } \\
\text { total County } \\
\text { beds (\%) }\end{array}$ & $\begin{array}{l}\text { Shelter beds per 10,000 extremely } \\
\text { poor persons (below 50\% of the } \\
\text { poverty line) }\end{array}$ \\
\hline Cluster 1 & 6908 & 57 & 198 \\
Cluster 2 & 4120 & 34 & 145 \\
Cluster 3 & 1194 & 9 & 100 \\
Total & 12,222 & & \\
\hline
\end{tabular}

How did the three clusters map onto the service geography of Los Angeles County? Answering this question required generating shelter profiles for each cluster. In April 2000, Los Angeles County had 12,222 beds that could be mapped, with the remaining 800 or so beds part of shelters (especially battered women) without a street address (Shelter Partnership, 2000).

Consistent with our expectations about marginal spaces, Cluster 1 contained over half of all shelter beds. This reflects the power of community opposition, often in the form of local NIMBY movements, to segregate services for homeless people in marginal spaces in the County (Takahashi, 1999), as well as the proximity to clients, themselves segregated to the lower income spaces of the County. When measured in per-capita terms of shelter beds per very poor persons (below $50 \%$ of the poverty line), we find in Table 2 that shelter beds remain disproportionately clustered in marginal spaces, at a rate of between $50 \%$ and $100 \%$ more than the transitional and prime spaces.

Service hubs in marginal spaces are critical elements in the constitution of material homeless survival. Several such hubs, operationalized as clusters of emergency shelters, were confirmed via our mapping procedures (see Fig. 2) and are mostly in Clusters 1 and 2, including Downtown Los Angeles, Hollywood, Santa Monica, Downtown Long Beach, Downtown Pasadena and West LA. In contrast, certain Cluster 3 areas (e.g. Beach Cities) had virtually no discernable service hubs. Shelters in Los Angeles County are thus heavily concentrated in marginal spaces, less so in transitional spaces, and almost not at all in prime spaces, thereby confirming the pattern found in Table 2.

\section{Homeless survival patterns}

We now amalgamate results of the cluster analysis with qualitative life histories, so as to better examine some of the interplay between the broader socio-economic spaces of the city and the lived experiences of the place-survival nexus. We are particularly interested in identifying the key features of each cluster space in terms of the place-survival nexus. Again, given that only 25 individuals were interviewed, we do not claim strong relationships between marginal, transitional and prime spaces and typical homeless survival behavior therein. However, our analysis does show broad differences in patterns of resources and survival strategies across the spatial types, demonstrating the utility of our

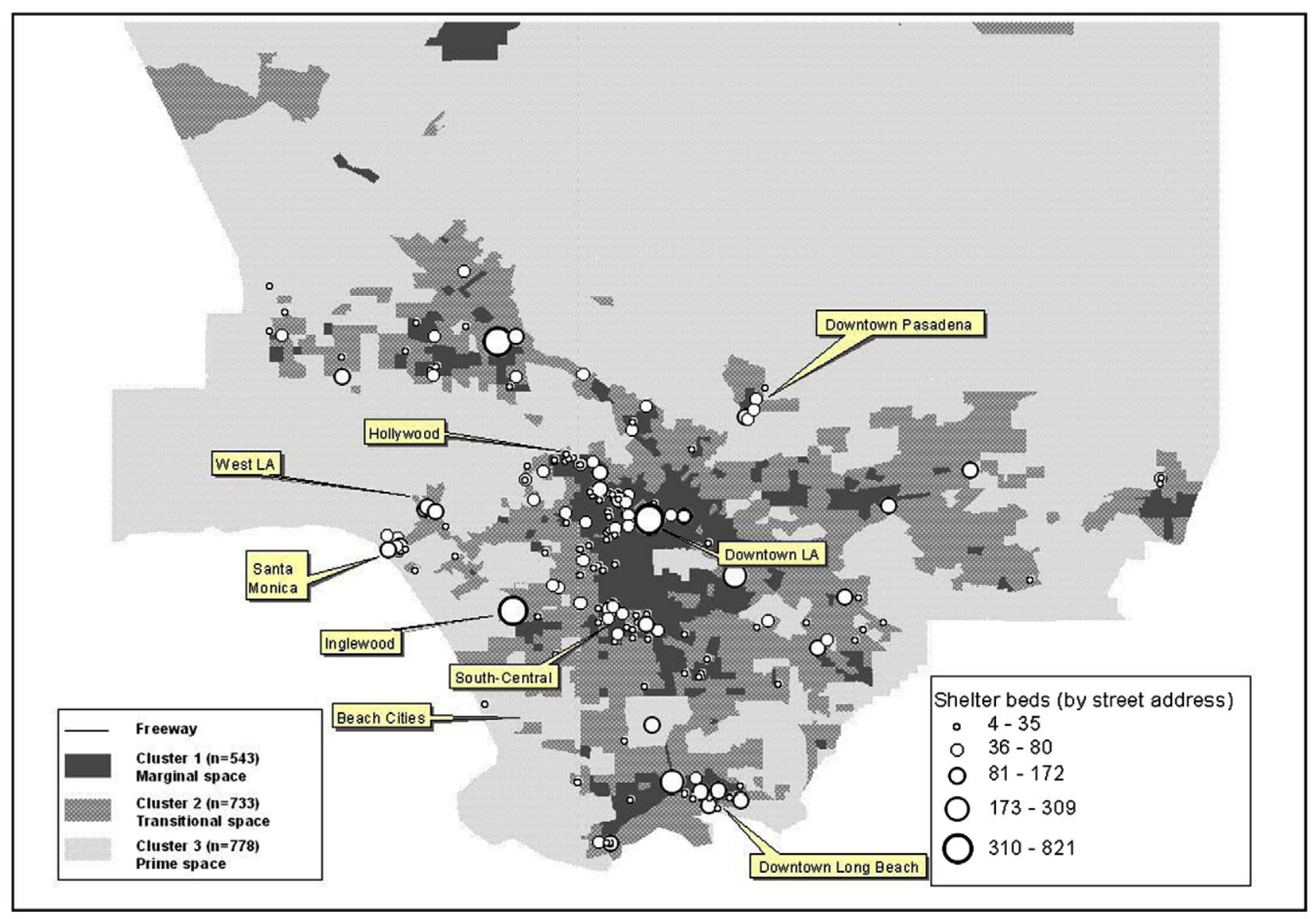

Source: Shelter Partnership (2000)

Fig. 2. Shelter beds by street address and cluster, South Los Angeles County, April 2000. 
unique approach to understanding the place-homeless survival nexus. As a first step to address these questions, Table 3 illustrates various demographic characteristics and survival strategies according to each spatial cluster.

Before exploring the differences in characteristics and survival strategies across clusters, we consider the similarities across the entire sample that demonstrates some aspects of the nature of homelessness in Los Angeles. ${ }^{4}$ The average ages of the individuals ( 37 to 42 years) were quite similar across the clusters and close to the median age ( 42 years) of the County homeless population (LAHSA, 2006). In terms of survival patterns, difficulty in obtaining food was generally not a major issue, demonstrating a general availability of soup kitchens, other food programs, and waste from commercial establishments. Contact with family was consistently reported among a substantial minority of respondents across the clusters, showing that not all persons experiencing homelessness are completely social isolated. Finally, welfare use - mostly the County's General Relief (GR) program, ${ }^{5}$ the local program for single indigent people - and the related inability to secure employment, was a common theme across the sample. Eighteen of the twenty-five individuals were receiving welfare benefits (with fourteen on GR, three on Temporary Assistance for Needy Families, and one on Supplemental Security Income), and eight were employed (one individual was working and on welfare simultaneously). Most of our informants mentioned various barriers to employment: lack of education, training, access to employment, mental and physical disabilities, and, of course, having no fixed address.

\section{The place-survival nexus in marginal space (Cluster 1)}

From our sample of 13 in Cluster 1, the place-survival nexus there was characterized by a high level of service use, itself influenced by the significant presence of shelters in marginal space. Individuals in marginal spaces experienced fewer instances of homeless episodes, and had spent less time on the street than individuals in the other clusters. This suggests that marginal spaces, with their greater concentration of services, may attract the recently dislocated homeless. Not surprisingly, then, individuals in marginal spaces were more likely to be service reliant, particularly with regards to obtaining a place to live. In effect, 11 of 13 were living in shelters, compared to 2 of 7 in transitional spaces and 1 of 5 in prime spaces. In turn, the strong presence of services in marginal spaces, particularly in the Skid Row area, effectively structured the everyday lives of those living in those spaces, even those on the streets, as illustrated by the experience of a 45-year old black man who had been homeless for five years in Skid Row. He recounted a typical day for us:

What I did yesterday, I spent the night over on Winston Street [on Skid Row]. I slept over there with a friend of mine in a tent. I

\footnotetext{
${ }^{4}$ Clearly our small sample size prevents us from identifying statistically significant differences in characteristics and survival behaviors between persons experiencing homelessness in the three clusters. However, in our exploratory analysis here, we identify interesting preliminary differences across the clusters that could be tested with larger sample sizes. In the interest of being explicit about our criteria accessing differences among persons across the three clusters, we use overt rather than covert criteria often used in statements of difference across categories in qualitative research (Robson, 1997:401). We identify a difference as meaningful if there is a $25 \%$ discrepancy in prevalence (for categorical variables like racial groups, shelter versus street residence, etc.) or average (for continuous variables like number of times homeless, average current time homeless, etc.) between the highest cluster and the lowest cluster. Although the $25 \%$ criteria are statistically arbitrary, they do provide a clear guideline from which to judge differences that are meaningful in an exploratory sense.

${ }^{5}$ Los Angeles County's General Relief program is available to documented persons that have been in the County at least 15 days and have less than $\$ 50$ in cash or in a bank account. The program provides $\$ 221$ in cash benefits per month for up to 9 out 12 months for persons deemed "employable" contingent on meeting employment program and workfare requirements, and 12 months per year for those deemed "unemployable" or physically unable to work (Los Angeles Coalition to End Hunger and Homelessness, 2005).
}

got up in the morning. I went to the Midnight Mission for breakfast, hung around over there for a little while, got a free haircut. Then after that, I came over and I went to my CA [Cocaine Anonymous] meetings. I'm mandated by the court to do outside meetings so I went to my 10 o'clock meeting. After I went to my CA meeting, I went back over here and I go to lunch. I hang out for a little while and I go back over to the VOA [Volunteers of America drop-in center] where they have the CA and they have a 2 o'clock group. So I go to 2 meetings a day and then I go over on Vermont [west of Skid Row] where my Proposition 36 outpatient program ${ }^{6}$ is and I go over there at 5:30. Then I come back over here and then sometimes all the shelter buses are gone so I end up sleeping outside again.

Despite the sustaining nature of Skid Row, some homeless people find it to be more of a trap than a key to subsistence and survival. In the words of a 38-year old black male who had been sporadically homeless over the past 10 years: "Skid Row becomes a trap for a lot of people. . .I don't want this to be my final destination." Although there is a large supply of services and emergency and transitional housing as well as some permanent subsidized housing on Skid Row, linkages to living wage employment is scarce and only a small minority is able to leave the area for rental housing (Marr, 2007).

For those living in shelters, the degree of structuring can be even stronger. The case of a 31-year old black woman, with two children staying at a shelter west of Downtown Los Angeles, is illustrative. As she explained:

Yeah, in terms of the services that I use right now, I am in a shelter in a fully furnished apartment with everything. I do have a case manager who is a very good case manager who checks in and I check in with her. You know, to see if I need anything or if she finds avenues that she can help me she gives me a call. Like this [the compensated interview] is helping me out and also sometimes if you're running low on food or toiletries or whatever, you can go to the office over there and they have food there. Not like a supermarket but they can give you things that will get you by. And they offer other support like if you have emotional problem, they say that their door is always open, you can come and talk to them and it's kinda like a togetherness or a unity there. They try to recognize and be appreciative of people and treat everybody with respect. Basically those are the things, other than the housing that they provide, they give you the forms that you need, have them completed, they do whatever they can to get you into housing. They do have a lot of services. I never knew these services exist because I never experienced this before but it's good to know that you can get help if you really need it. There are services here.

In addition to receiving such institutional assistance covering a variety of aspects of daily life, some individuals even worked for service providers. For example, one 33-year old black male with several bouts of homelessness and substance abuse, worked part-time for a shelter, and once helped count homeless people in Long Beach. His heavy reliance on the shelter and other organizations to subsist illustrates what has been identified as the "institutionally adapted" homeless (Snow and Anderson, 1993, pp. 55-57).

Given their high level of service use, individuals in marginal spaces were less likely to engage in more makeshift strategies to survive, such as recycling and panhandling, unless they were substance abusers who needed cash daily to sustain their habits. Indeed, why would people like the 31-year old mother mentioned above engage in such activities when all her daily needs are pro-

\footnotetext{
${ }^{6}$ California State Proposition 36, the "Substance Abuse and Crime Prevention Act" was passed in 2000 and changed state law to allow first- and second-time nonviolent drug possession offenders to receive substance abuse treatment rather than incarceration.
} 
vided by the shelter? Moreover, given higher levels of surveillance and containment, those on Skid Row are increasingly unable to access the more mainstream spaces of Downtown Los Angeles to panhandle or recycle. As noted by one of our informants, police and private security forces often prevent Skid Row residents from leaving the district by patrolling nearby business districts.

You go to China Town [sic - he is referring to the Little Tokyo commercial district immediately north of Downtown Skid Row] right over there, as soon as the police see you over there, they are going to follow you all through China Town just because you different. First of all, you Black. They gonna follow you all around [pounding table] and sit there on the corner until you get out of sight and I bet before you walk two more blocks there is gonna be another police officer come in. I would assume that they got on their dispatch unit and said, 'We have a suspicious suspect.' All of a sudden, you become suspicious. ... It's either private security or police officers, but you are not allowed. You can go in there and they might not harass you but they'll make their presence visible to you so you get away.

This interviewee's experience demonstrates how living in a shelter in a marginal space proximate to a commercial district can subject homeless persons, especially members of disadvantaged racial and ethnic groups, to surveillance and thus encourage them to engage in daily activities within specialized service settings. Although this informant conducted most of his daily activities within an emergency shelter, a soup kitchen, and other community facilities, his need to support a crack cocaine addiction drove him to continue to panhandle. Akin to the Duneier's (1999) street vendors swayed to that work by new laws intended to protect First Amendment rights, one unintended consequence of increased policing of Little Tokyo was simply displacing and reshaping panhandling activity. This interviewee improved his physical appearance with clean clothing, headed south of Skid Row to a gas station used by commuters, and posed as having run out of gas a day before payday to solicit donations from customers.

\section{The place-survival nexus in transitional space (Cluster 2)}

From our sample of 7, the place-survival nexus in Cluster 2 was characterized by makeshift patterns that reflected much lower levels of service use. This was most likely due to lower concentration of services in transitional spaces, as well as the avoidance of marginal spaces and their service offerings by interviewees.

A 46-year old African-American woman in the San Gabriel Valley (a suburban area with relatively few formal services), for example, spends nights with friends or her son, at a local Denny's, or in her car. She has also slept in the emergency room of a hospital and in the lobby and hallways of a motel that she had stayed in during her descent into homelessness. Given her extremely unstable residential situation, her daily routines are not structured by service providers. She is unable to stay for long periods with friends or her son because of a shortage of space and the presence of their families. Although she works short-term jobs through temporary agencies, her income is neither sufficient nor stable enough to rent an apartment. She has been unable to collect welfare benefits because of her employment in temporary jobs. She makes ends meet with her income from these jobs, as well as through recycling, panhandling and eating meals with friends when visiting them. Since there are no soup kitchens in the area, there are days where she makes do as best she can, and occasionally does not eat at all. She uses restaurant toilets as much as possible, but finds it especially difficult to find a place to wash and shower.

In nearby West Covina, a young man of African-American, Puerto Rican, and Filipino descent, stays at the business of his cousin's mother-in-law without her permission. His cousin is in a similar precarious housing situation and they help each other out. They have to leave the business by 7 A.M. and cannot return until 9 P.M. Since his current spell of homelessness began, this informant has slept on the street, in abandoned buildings and in a winter shelter. To get by, he currently relies on day labor, selling drugs, recycling, and occasional small loans from friends. He does not get GR, but has applied for it and found the GR-based job training to be unhelpful and was subsequently terminated, although he was unsure if it was because of noncompliance or a bureaucratic mix up. He worked about 15 days in the past month, getting jobs from Labor Ready, Manpower, and other "temp" agencies, through word of mouth, and on occasion, off of a street corner hiring site. Most of his work has been in construction, shipping, and moving. The vast majority of his days are spent either working or looking for work at agencies, on the street networking with other homeless persons, and on the Internet at the local library.

The shortage of formal services did not seem to bother several of the homeless individuals interviewed in transitional spaces; in fact, some preferred to avoid service-rich areas, especially if they are located in marginal spaces. For example, a 65-year old white male of French Canadian descent, is experiencing his third spell of homeless and is staying at the San Fernando Valley Cold Wet Weather shelter operated by a local nonprofit organization. He alternates between staying in motels, shelters, and the streets, and studiously avoids marginal spaces such as Downtown's Skid Row.

I told somebody, 'You'll never get me to live in [downtown] LA.' GR was gonna send me to LA, to a hotel down there and I said, 'No thank you. I'd as soon live on the street than live in a hotel in downtown LA where there are 20,000 people out of work down there. How am I gonna do down there?' I said, 'I'll stay in the Valley where there's not that many people out of work. I know the Valley better than I know LA because I worked for Goodwill.

During warmer weather, he spends most of his days on the street in the San Fernando Valley, but finds it very difficult to access a public toilet. Similarly, a Chinese-Indonesian immigrant ${ }^{7}$ in his 40 s fears having to search for a new place to sleep if displaced: "It could be troublesome, because so far I haven't been moving from one place to another, I always sleep in the same spot. But for most people, it could be difficult because some places they don't want you. If they say no then you are still violating by going into their area, then they're going to hire security." While the surveillance described above by the cluster 1 informant limited his daily rounds and confined him to a shelter, this interviewee's description shows how public and private security agents can complicate to a greater extent the sleeping arrangements of those without access to shelters, a group more prevalent in Cluster 2.

\section{The place-survival nexus in prime space (Cluster 3)}

From our sample of 5, the place-survival nexus in Cluster 3 was characterized by a nearly complete lack of service utilization. This makeshift lifestyle is clearly illustrated by a woman informant who lives on the streets of the "beach cities," and has managed to do so without services by honing her survival techniques over time. She uses restaurants, laundry mats, public showers on the beach, local churches, "dumpster diving," and occasionally panhandling and

\footnotetext{
${ }^{7}$ Few immigrants were among our sample (3 of 25 , or $12 \%$ ) considering their proportion of the total Los Angeles County population (36\% in 2000). Although no data exists on the proportion of immigrants among homeless people in Los Angeles, Latinos, a heavily immigrant ethnic group, are underrepresented, reflecting higher levels of social capital and employment, as well as a willingness to overcrowd, than poor blacks and to a lesser extent, whites (Gonzales-Baker, 1996; LAHSA, 2006). Interestingly, immigrants from our sample concentrated in transitional and marginal spaces, likely reflecting the higher concentration of housed immigrants living in these clusters.
} 
Table 3

Demographic and survival by spatial cluster.

\begin{tabular}{|c|c|c|c|}
\hline & $\begin{array}{l}\text { Marginal } \\
\text { spaces } \\
(n=13)\end{array}$ & $\begin{array}{l}\text { Transitional } \\
\text { spaces } \\
(n=7)\end{array}$ & $\begin{array}{l}\text { Prime } \\
\text { spaces } \\
(n=5)\end{array}$ \\
\hline \multicolumn{4}{|l|}{ Demographic data } \\
\hline \multicolumn{4}{|l|}{ Race } \\
\hline African-American & $61 \%$ & $14 \%$ & $20 \%$ \\
\hline Latino & $15 \%$ & $28 \%$ & $20 \%$ \\
\hline White & $23 \%$ & $43 \%$ & $60 \%$ \\
\hline Asian & Zero & $28 \%$ & Zero \\
\hline With children & $31 \%$ & Zero & Zero \\
\hline Immigrant & $8 \%$ & $28 \%$ & Zero \\
\hline Average age & 37 & 42 & 42 \\
\hline \multicolumn{4}{|l|}{ Vulnerabilities (self-reported) } \\
\hline Veteran & $18 \%$ & $14 \%$ & Zero \\
\hline Foster care & $8 \%$ & Zero & $20 \%$ \\
\hline Substance abuse & $61 \%$ & $28 \%$ & $40 \%$ \\
\hline Domestic violence & $23 \%$ & Zero & $20 \%$ \\
\hline Criminal background & $38 \%$ & $28 \%$ & $40 \%$ \\
\hline \multicolumn{4}{|l|}{ Residence/shelter/place } \\
\hline In shelter & $85 \%$ & $28 \%$ & $20 \%$ \\
\hline On the street & $15 \%$ & $71 \%$ & $80 \%$ \\
\hline Average number of times homeless & 3.1 times & 4.4 times & 4 times \\
\hline Average current time homeless & 18 months & 31 months & 86 months \\
\hline \multicolumn{4}{|l|}{ Economic/material subsistence } \\
\hline On welfare & $77 \%$ & $71 \%$ & $60 \%$ \\
\hline Employed & $38 \%$ & $28 \%$ & $20 \%$ \\
\hline Difficulty in obtaining food & $15 \%$ & $28 \%$ & $20 \%$ \\
\hline Difficulty in finding a bathroom & $8 \%$ & $71 \%$ & $40 \%$ \\
\hline Recycled & $15 \%$ & $71 \%$ & $40 \%$ \\
\hline Panhandled & $15 \%$ & $43 \%$ & $40 \%$ \\
\hline \multicolumn{4}{|l|}{ Social subsistence } \\
\hline Contact with family & $38 \%$ & $28 \%$ & $40 \%$ \\
\hline Essentially alone & $31 \%$ & $14 \%$ & $20 \%$ \\
\hline
\end{tabular}

recycling to get by. She has built up an extensive local knowledge of the area, thereby giving her an advantage over the newly-homeless: "They don't know about these places that I mentioned to you. They're on the streets, they don't know nothing! Me, I'm a survivor. I'm from way back, you know. So it's just a piece a cake for me." Her scavenging techniques speak of her ability to, in her view, "thrive" in her own uniquely "rich" sustaining environment.

They [bagel shops in Manhattan Beach] basically know that people are going to be back there and they put it [unsold food] in plastic bags and put it right on top. You open the bag, you get what you want and then you close the bag up nicely so the birds aren't gonna be attackin' their trash cans and stuff like that. If you're walking past the place, then why not? You know, stop and see if there's fresh bagels. Even my favorite donuts, I can go to any of these donut shops around here and they won't have my favorite donut but I'll go in that dumpster out there and there's my favorite donut, you know? That's weird, huh? Nothing is wrong with the food at all. Then again, do you know that there is a lot of places their policy is that like Dominos for instance and Pizza Hut also, that if someone calls up and it's a cancelled order, they'll just, if you go in there and say, 'Hey, do you got any cancelled orders today?' I came out with three big boxes full of pizzas...there's lots of places you just say, 'Hey, you got any cancelled orders?' You never can starve in LA. You just can't!

This interviewee is careful not to allow her scavenging activities cause inconvenience to the commercial establishments that serve as her source of food, demonstrating a need for a particular keenness when surviving outside the coverage of specialized service providers.

A further illustration is a 30 -year old white male who is experiencing his first stint of homelessness aside from brief stints while traveling in South America. He lives in a tent in the remote coastal area just northwest of Santa Monica, has very few resources, and survives solely on food lines. He has lost all of his identification and therefore has been unable to apply for GR or Food Stamps. He jogs one hour down to the Santa Monica beach area to go to food lines almost daily:

Let's see, I get up from my camp, it probably takes me about an hour to get up and get cleaned up and I jog in. It's kinda like a long jog. It takes me about another hour to get to town. So that's two hours and then there is a food line...You could say that takes two hours, you have to wait in line there usually. So that's four hours and then from there I come up to the park here and wait around another couple hours and there is another food line and then jog home for another hour and that takes care of the day, basically.

This informant's experiences show a great deal of inconvenience and need for discipline and resolve in subsisting in a remote area far from services or a sustaining commercial district, contrasting with the previous informant's account.

A final example of this makeshift survival strategy associated with prime space is provided by a 37-year old Latino male who has generally been homeless since age 16 . At the time one of us met him, he was staying in his car in the high-desert Lancaster area north of Los Angeles, where he had been living for the past five months. His routine involved moving nightly from one retail business parking lot to another with a "cavalry" of about six other homeless people living in their cars. They seek places that are quiet and safe and move whenever the police tell them to do so. He was able to buy his late 1980 s model Honda Civic for around $\$ 200$ with a GR check, and paid for tags and insurance with checks from subsequent months. Despite having proper registration and insurance he is often pulled over by the police and "harassed." He is well known to the police who often give him open container tickets for drinking in the park. He recently spent a week in LA County Jail when his tickets built up to a warrant for arrest. Prior to buying his car, he was "roughing it," living in a park and sleeping in a sleeping bag, Occasionally, when the weather became severely inclement, he would move into a Cold/Wet Weather Shelter, but that was a last resort as he did not like staying in such facilities because he found it difficult to get along with the other residents.

\section{Discussion and conclusion}

Our research focused on whether our innovative approach enabled a potentially broader, more extensive and more variegated understanding of place-survival among homeless people. We found it did in at least two ways. First, the tripartite typology proved useful for both the cluster analysis and the interviews. The results of the quantitative analysis were statistically significant and quite efficient at breaking down a very complex global city-region into three distinct cluster spaces. The cluster analysis allowed a County-wide application of the typology, thereby producing a more extensive and variegated set of places to sample from. This also allowed us to map the distribution of emergency shelters onto the three clusters, the result being a high concentration in marginal spaces with low socio-economic characteristics. The results of the qualitative analysis showed, even with a limited sample, some important exploratory differences in the key features of the place-survival nexus for each cluster.

Second, the ability to combine the quantitative and qualitative methods, along with the allied ability to link space and place, proved advantageous in better understanding the place-survival nexus. More generally, we were able to demonstrate the constrain- 
ing effects of the socio-geographic containers of urban spaces on the self-selecting survival strategies and experiences of places among the 25 individuals, without falling victim to the ecological fallacy. We were also able to explore the place-survival nexus in areas rarely studied in the literature, those suburban and exurban locales (e.g. Beach Cities, San Fernando Valley, West Covina, Lancaster/Palmdale) where alternative strategies were deployed. These included the use of vacant lots, cars and restaurants. Interestingly, and despite the dearth of services, individuals in service-poor transitional and prime spaces saw no need to migrate to marginal spaces - why? We know from the interview data that there are significant issues of stigma attached to marginal spaces, the sense of downward mobility, as well as perhaps too much competition. Even more interesting was the ability of homeless people to persist in such unpromising locales, allowing us to chronicle the place-survival nexus beyond the confines of Skid Row and other typical sustaining habitats. These findings also support the conclusion that homeless people are not idle and unwitting in their actions (Duneier, 1999; Hopper, 2003; Snow and Anderson, 1993; Snow and Mulcahy, 2001). Instead, we have shown that homeless persons actively forge survival strategies amid the economic, social and political resources and constraints of their environments, thus suggesting a kind of elective affinity between urban spaces and behavior. This adds to our initial contentions that despite mounting pressures on public space, homeless people endure nonetheless and exercise considerable agency while doing so.

Given our findings, research that depicts a generic, one-sizefits-all relationship between urban space/place and homeless survival is likely misguided. The unequal distribution of resources helps to pattern (but not determine) the survival of homeless persons in the different types of spaces. At one extreme, those in resource-rich marginal spaces were generally more reliant upon the institutions that provide relief services. While the daily routines and lifestyle of those who inhabit transitional spaces fluctuates between service dependence and more resourceful independence, those living in prime spaces, and thus at the other extreme, tend to make do without accessible institutional resources and survive via more makeshift, shadow work, and scavenging strategies.

There were, of course, some important limitations to the approach and particularly the actual study. We are by no means rubber-stamping this approach. Although the variation in subsistence strategies across the clusters demonstrates the utility of the tripartite division based on Snow and Mulcahy's conceptualization, future research may benefit from using a more complex typology that allows for more variation within prime, marginal, and transitional spaces. For example, within each spatial type, further categorizations could be made to allow for variation in factors such as policing strategies, transportation access, and mixture of public and private ownership to assess their impact on subsistence strategies. Other shortcomings came from the (unavoidable) reliance on census data, making it impossible to understand prime/marginal/transitional spaces in terms of activity and employment (Ellis et al., 2004). Subsequent studies, however, could use the US Census Transportation Planning Package to better grasp the diurnal shifts between place of residence and place of work, and which would allow classification of parts of the County according to daytime workplace populations. It should be noted that homeless individuals can be quite mobile, such that some of them habitually move between marginal, transitional and prime spaces within a single day. ${ }^{8}$ Moreover, the use of census tracts carries several well-known limitations, including that not all of them are of equal size or population,

\footnotetext{
${ }^{8}$ For discussion of intra-city mobility among the homeless, see DeVerteuil (2003),
} Lee and Price-Spratlen (2004) and Snow and Anderson (1993). that people move freely among them, and that contiguity can create special effects - living in a marginal tract surrounded by others (the underclass or concentrated poverty thesis) is most likely different to living in a marginal tract right next to transitional or prime spaces. For instance, the pattern within Downtown is certainly more complex than the cluster designation suggests. While the area is undergoing significant revitalization - as reflected in such mega-projects as the Staples Center (1999), the Cathedral of Our Lady of the Angels (2002) and the Walt Disney Concert Hall (2003), as well as the recent surge in loft redevelopment and the construction of new, high-end apartment complexes - Downtown remains quite marginal in the evenings, still more the domain of the homeless than Yuppies.

A second source of limitations is the sample size, which is clearly too small to talk about typical patterns across each cluster space. But we can argue that this is not an inherent problem of our approach, but rather of the modest sample size. Future research could employ a larger study that would consolidate, or potentially challenge, our results here. We can thus offer a broader conclusion than simply "space matters." Rather, we show how it matters, as an outcome of the balance between place-based constraints and individual agency and self-selection. Prime spaces high on a socio-economic gradient, either through NIMBYism or less assertive planning measures, encompass few shelters and thus survival strategies are more makeshift. Marginal spaces at the bottom of the socio-economic gradient contain more ample, although insufficient, amounts of shelters and thus homeless experiences are more shaped by institutional contexts. The insights from our contextual approach could be extended beyond the homeless to include the place-dependent experiences of other vulnerable, place-bounded groups, such as recent immigrants and recently discharged prisoners.

\section{Acknowledgements}

The research on which the paper is based was supported by a grant from the National Science Foundation (SES-0213372, David Snow, Principal Investigator). We would like to thank the National Science Foundation and all of the individuals who responded to interviews used in this paper.

\section{References}

Baldwin, D (1998) The subsistence adaptation of homeless mentally ill women. Human Organization 57, 190-199.

Burt, M, Aron, L and Lee, E (2001) Helping America's Homeless: Emergency Shelter or Affordable Housing? The Urban Institute Press, Washington, DC.

Cohen, C and Sokolovsky, J (1989) Old Men of the Bowery: Strategies for Survival among the Homeless. Guilford Press, New York.

Central City Association (2002) Downtown's Human Tragedy: It's Not Acceptable Anymore. Center City Association, Los Angeles.

Cloke, P, Milbourne, P and Widdowfield, R (2002) Rural Homelessness. Policy Press, Bristol.

Davis, M (1992) City of Quartz: Excavating the Future in Los Angeles. Verso, New York. Dear, M, Wolch, J and Wilton, R (1994) The service hub concept in human services. Progress in Planning 42, 179-267.

DeVerteuil, G (2003) Homeless mobility, institutional settings, and the new poverty management. Environment and Planning A 35, 361-379.

DeVerteuil, G (2005) Welfare neighborhoods: anatomy of a concept. Journal of Poverty 9, 23-41.

DeVerteuil, G (2006) The local state and homeless shelters: beyond revanchism? Cities 23, 109-120.

Dordick, G (1997) Something Left to Lose: Personal Relations and Survival Among New York's Homeless. Temple University Press, Philadelphia.

Duncan, J (1983) Men without property: the tramp's classification and use of urban space. In Readings in Urban Analysis, R Lake (ed.), pp. 86-102. Rutgers University Press, New Brunswick.

Duneier, M (1999) Sidewalk. Farrar, Straus, and Giroux, New York.

Ellis, M, Wright, R and Parks, V (2004) Work together, live apart? Geographies of racial and ethnic segregation at home and at work. Annals of the Association of American Geographers 94, 620-637.

Gonzales-Baker, S (1996) Homelessness and the Latino paradox. In Homelessness in America, J Baumohl (ed.), pp. 132-140. The Oryx Press, Phoenix. 
Gounis, K (1992) The manufacture of dependency: shelterization revisited. New England Journal of Public Policy 8, 685-693.

Hopper, K (2003) Reckogning with Homelessness. Cornell University Press, Ithica.

Hopper, K, Susser, E and Conover, S (1985) Economies of the makeshift: deindustrialization and homelessness in New York City. Urban Anthropology 14(1-3), 183-236.

Koegel, P, Sullivan, G, Burnam, A, Morton, S and Wenzel, S (1999) Utilization of mental health and substance abuse services among homeless adults in Los Angeles. Medical Care 37(3), 306-317.

Law, R (2001) 'Not in my city': local governments and homelessness policies in the Los Angeles metropolitan region. Environment and Planning C 19, 791-815.

Lee, B and Price-Spratlen, T (2004) The geography of homelessness in American communities: concentration or dispersion? City and Community 3, 3-27.

Levia, D and Page, D (2000) The use of cluster analysis in distinguishing farmland prone to residential development: a case study of Sterling, Massachusetts. Environmental Management 25, 541-548.

Logan, J and Molotch, H (1987) Urban Fortunes: The Political Economy of Place. University of California Press, Berkeley.

Lofland, J, Snow, D, Anderson, L and Lofland, L (2006) Analyzing Social Settings: A Guide to Qualitative Observation and Analysis, 4th ed. Thomson/Wadsworth, Belmont.

Los Angeles Coalition to End Hunger and Homelessness (2005) People's Guide to Welfare, Health, and Other Services. Los Angeles Coalition to End Hunger and Homelessness, Los Angeles.

Los Angeles Homeless Services Authority (LAHSA) (2006) 2005 Greater Los Angeles Homeless Count. Los Angeles Homeless Services Authority, Los Angeles.

Marr, M (2007) Better Must Come: Exiting Homelessness in Two Global Cities, Los Angeles and Tokyo. Doctoral Dissertation, University of California at Los Angeles.

Merrifield, A (2000) The dialectics of dystopia: disorder and zero tolerance in the city. International Journal of Urban and Regional Research 24, 473-489.

Mitchell, D (1997) The annihilation of space by law: the roots and implications of anti-homeless laws in the United States. Antipode 29, 303-336.

Molina, G (1998) Social Networks Among the Inner-City Homeless: A Comparative Study of Latino and African-American Men. Doctoral Dissertation, University of California at Los Angeles.

National Coalition for the Homeless (NCH) (2007) Illegal to be Homeless: The Criminalization of Homelessness in the United States. National Coalition for the Homeless, Washington, DC.
Passaro, J (1996) The Unequal Homeless: Men on the Street Women in Their Place. Routledge, New York.

Robson, C (1997) Real World Research: A Resource for Social Scientist and Practitioners. Blackwell Publishers, Malden.

Rogerson, P (2001) Statistical Methods for Geography. Sage Publications, Thousand Oaks.

Rollinson, P (1990) The story of Edward: the everyday geography of elderly single single room occupancy (SRO) hotel tenants. Journal of Contemporary Ethnography 19(2), 188-206.

Rowe, S and Wolch, J (1990) Social networks in time and space: homeless women in skid row, Los Angeles. Annals of the Association of American Geographers 80, 184 204.

Ruddick, S (1996) Young and Homeless in Hollywood: Mapping Social Identity. Routledge, New York.

Sassen, S (2001) The Global City. Princeton University Press, Princeton.

Scott, A (2001) Introduction. In Global City-Regions: Trends, Theory, Policy, A Scott (ed.), pp. 1-8. Oxford University Press, Oxford.

Shelter Partnership (2000) Short-Term Housing Directory of Los Angeles County, April 2000. Shelter Partnership, Inc., Los Angeles.

Snow, D and Anderson, L (1993) Down on Their Luck: A Study of Homeless Street People. University of California Press, Berkeley.

Snow, D and Mulcahy, M (2001) Space, politics, and the survival strategies of the homeless. American Behavioral Scientist 45, 149-169.

Park, R and Burgess, E (1925) The City: Suggestions for Investigation of Human Behavior in the Urban Environment. University of Chicago Press, Chicago.

Takahashi, L (1999) Homelessness, AIDS, and Stigmatization in the United States at the End of the Twentieth Century. Oxford University Press, Oxford.

US Census Bureau (2000) 2000 US Census of Population.

US Census Bureau (2008) 2007 Population Estimates.

Wolch, J (2008) Intransigent LA. Geoforum 39, 543-545.

Wolch, J and Dear, M (1993) Malign Neglect: Homelessness in an American City. Jerry Bass Publishers, San Francisco.

Wolch, J and DeVerteuil, G (2001) New landscapes of urban poverty management. In TimeSpace, J May and N Thrift (eds.), pp. 149-168. Routledge, London.

Wright, T (1997) Out of Place: Homeless Mobilizations Subcities and Contested Landscapes. SUNY Press, Albany. 